\title{
Stock Market Crisis Identification as a Factor Ensuring Country's Economic Security
}

\author{
M.E. Konovalova ${ }^{1 *}, O . Y u$. Kuzmina ${ }^{1}$, V.Ya. Vishnever ${ }^{1}$, and S.Yu. Salomatina ${ }^{1}$ \\ ${ }^{*}$ Corresponding author: mkonoval@mail.ru. \\ ${ }^{1}$ Samara State University of Economics, Samara, Russia
}

\begin{abstract}
The article reviews the issues of the economic security of the country from the standpoint of identification of financial crises. The essence and content of a financial crisis are given, characteristic traits of a stock market bubble as an integral part of a stock market crisis are singled out. Special emphasis is laid on the study of the existing methods of identification and measurement of bubbles. The authors analyze the modern stock market crises, describe the Russian stock market vulnerability factors. The article evaluates the possibility for the origination of a stock market crisis in Russia on the modern stage resulting in the creation of a multi-factor stock market bubble identification model. The authors justify proposals and recommendations for the elimination of the existing Russian stock market problems aimed at removal of the economic security threats of the country.
\end{abstract}

Keywords: financial crisis, stock market, stock market bubble, financial crisis ratios, economic security.

\section{Introduction}

A stock market is meant to perform one of the most important functions, which lies in the attraction of investments in the real sector of the economy. However, when the market functioning mechanisms get broken and the market is no longer assessing the value of financial instruments adequately, the probability of the origination of such phenomenon as a stock market crisis is high. Stock market crises take place fairly often, bear a systemic character and may distribute globally in case of turmoil at one of the markets.

\section{Problem Statement}

The article is dedicated to research of the issue of the identification of financial crises for minimization of their negative influence on the economic security of the country. It is the stock market sector, that many financial crises start from, thus, an analysis of the regularities of stock market crises seems the most interesting [1]. To overcome a crisis, one needs to be ready for it; timely identification of a stock market crisis will not only enable the investors to make correct decisions, but will help state authorities mitigate its negative effects or prevent it altogether.

\section{Research Questions}

The following tasks need to be fulfilled to solve the problem set in the course of the research. Firstly, to single out characteristic traits of a stock market bubble and review the existing methods of its identification and measurement on the securities market. Secondly, to carry out a lookback analysis of the reasons and factors affecting the origination of crises on the Russian stock market. Thirdly, to determine the Russian securities market crisis vulnerability factors and propose instruments of raising its financial stability.

\section{Purpose of the Study}

The main purpose of the study is the development of the theoretical and methodological provisions of the financial crisis establishment and development process. Neither foreign nor Russian scientific publications have the unified and generally accepted approach towards forecasting of securities market crises and bubbles forming the request of the society for fundamental and exploratory research of the issues related to early identification of financial bubbles. One also needs to justify the main areas of the improvement of financial relationships causing an increase in the stock market functioning efficiency. 


\section{Research Methods}

The following general scientific methods of cognition of phenomena and processes serve as a methodological basis for the research: methods of logical, dialectic and historical analysis, the systemic approach towards the analysis of crisis phenomena on financial markets and the development of methods of their early identification. Methods of statistical, econometric analysis, economic and mathematical modeling are also widely used. These methods jointly with theoretical provisions and economic information allow securing the reliability and justification of the results received and conclusions made in the course of the research.

\section{Findings}

\subsection{Theoretical Bases of the Study of the Content of Financial Crises}

Having reviewed various theoretical perceptions of the nature of financial crises and their quantitative characteristics, we have come to the conclusion that no unified approach towards the understanding of the problem has been formed yet. Indeed, quantitative characteristics of bubbles are quite subjective and significantly vary depending on the market character, national identity, scale and many other factors [2]. Not too much studies of this sector have been carried out in Russia so that some bubble parameters could be applied with confidence, and the use of foreign methods does not seem correct in view of serious differences between the markets. Timely identification of a stock market crisis will not only enable the investors to make correct decisions, but will help state authorities mitigate its negative effects or prevent it altogether [3]. The development of the methodology required for crisis diagnosing will solve this problem.

\subsection{The Stock Market Bubble Concept and Identification}

Judging by the history of stock market crises, it becomes obvious that they are most often triggered by a stock market bubble. The term 'bubble' is used to describe stable excess of the asset price over its fundamental value. That means that in order to identify it, one needs to know the fundamental asset value, which is not simple and obvious to calculate; the period and amount of excess of the asset price over its fundamental value. Multiple attempts of researchers and analysts at specification of these criteria have brought no real results; all received results are rather subjective and cannot be fixed once and for all. In view of this, a generally accepted quantitative definition of a stock market bubble still does not exist [4].

There are many ways to identify bubbles. The main of them are: the macroeconomic ratio method, technical analysis, economic, physical, econometric methods, instruments of the behavioral finance theory [5], experimental modelling of stock market bubble forming. It is insufficient to use just one approach due to the risk of unavoidable omissions intrinsic to one method taken separately. So it is more correct to apply a complex analysis of bubble identification enabling to characterize various stock market aspects: the behavioral factor, macroeconomic environment, systemic mistakes and influence of various factors [6].

\subsection{Analysis and Evaluation of the Probability of Financial Bubble Origination on the Russian Stock Market}

The financial bubble identification process has been analyzed in three steps: testing of the Russian stock market efficiency, testing of financial asset prices consisting of a macroeconomic, factor and fractal analysis of the prices of financial instruments circulating on the Russian stock market. The received results have been interpreted in the conclusion of the research from the standpoint of the evaluation of the probability of stock market bubble origination.

Since bubble inflation is largely facilitated by the behavior of the participants adopting various decisions based on the information existing on the market, one needs to check the information efficiency of the market with the help of the hypothesis phrased by E. Fama [7]. The Durbin-Watson test detecting the presence or absence of autocorrelation in the asset price dynamics has been used to determine the efficiency degree. The Russian market exhibits autocorrelation between the levels of the range starting at lag 7 (except for separate periods when the dependence has been identified at lower lags) (table 1). Thus, a conclusion can be made that the participants adopting investment decisions have been relying on the information on previous index dynamics, i.e. the players' behavior is characterized with mimical and imitative elements.

Table 1. Values of the Durbin-Watson statistics from 2003 to quarter I 2019.

\begin{tabular}{|c|c|c|c|c|c|}
\hline Period & \multicolumn{5}{|c|}{ Lag } \\
\hline & 6 & 7 & 8 & 9 & 10 \\
\hline 2003 & $\mathbf{1 . 0 4 6}$ & $\mathbf{1 . 0 6 5}$ & $\mathbf{1 . 0 9 8}$ & $\mathbf{1 . 1 1 5}$ & $\mathbf{1 . 1}$ \\
\hline 2004 & $\mathbf{1 . 1 5 1}$ & $\mathbf{1 . 1 0 9}$ & $\mathbf{1 . 1 7 8}$ & $\mathbf{1 . 1 5 6}$ & $\mathbf{1 . 0 4 2}$ \\
\hline 2005 & 1.987 & $\mathbf{1 . 0 7 1}$ & $\mathbf{1 . 0 4 6}$ & $\mathbf{1 . 0 1 1}$ & $\mathbf{1 . 0 3 4}$ \\
\hline 2006 & 1.989 & $\mathbf{1 . 0 8 1}$ & $\mathbf{1 . 1 0 1}$ & $\mathbf{1 . 0 4 6}$ & $\mathbf{1 . 0 8 7}$ \\
\hline
\end{tabular}




\begin{tabular}{|c|c|c|c|c|c|}
\hline 2007 & 2 & $\mathbf{1 . 0 6 9}$ & $\mathbf{1 . 0 2}$ & $\mathbf{1 . 0 6}$ & $\mathbf{1 . 0 2 6}$ \\
\hline 2008 & $\mathbf{1 . 5 8 4}$ & $\mathbf{1 . 5 2 7}$ & $\mathbf{1 . 5 8 4}$ & $\mathbf{1 . 5 3 2}$ & $\mathbf{1 . 5 3 6}$ \\
\hline 2009 & $\mathbf{1 . 0 7 8}$ & $\mathbf{1 . 1 0 9}$ & $\mathbf{1 . 0 8 9}$ & $\mathbf{1 . 0 9 4}$ & $\mathbf{1 . 1 0 8}$ \\
\hline 2010 & 2.009 & $\mathbf{1 . 0 4}$ & $\mathbf{1 . 0 4 5}$ & $\mathbf{1 . 0 3 2}$ & $\mathbf{1 . 0 2 9}$ \\
\hline 2011 & 1.993 & $\mathbf{1 . 0 7 9}$ & $\mathbf{1 . 0 3 6}$ & $\mathbf{1 . 1 1 8}$ & $\mathbf{1 . 0 8 8}$ \\
\hline 2012 & 1.786 & 2.045 & 1.927 & 1.828 & 2.059 \\
\hline 2013 & 1.855 & 1.932 & 1.963 & 1.93 & 1.959 \\
\hline 2014 & 1.729 & 1.745 & $\mathbf{1 . 6 0 4}$ & 2.098 & $\mathbf{2 . 4 3 7}$ \\
\hline 2015 & 1.828 & 1.763 & $\mathbf{1 . 5 9 7}$ & $\mathbf{2 . 4 1 1}$ & $\mathbf{2 . 4 4 4}$ \\
\hline 2016 & 1.827 & 1.935 & $\mathbf{1 . 2 9 7}$ & $\mathbf{2 . 2 8 7}$ & 1.721 \\
\hline 2017 & 2.102 & 1.739 & 1.979 & 2.073 & 2.067 \\
\hline 2018 & $\mathbf{1 . 0 4 3}$ & 1.744 & 2.048 & 1.974 & 2.04 \\
\hline Quarter I 2019 & $\mathbf{2 . 2 8 6}$ & $\mathbf{2 . 2 9 1}$ & $\mathbf{2 . 3 1 1}$ & 2.259 & 2.102 \\
\hline
\end{tabular}

Source: Authors.

On the second step, we have tested the asset price by three various means. The stock market role in the national economy has been identified using the macroeconomic analysis. The stock market capitalization-to-GDP - MCap/GDP ratio (the Buffett Indicator) has been used as the indicator. The analysis has been carried out in dynamics with identification of the average threshold value for the researched period (62\%). The current ratio exhibits the value of $42-$ $43 \%$ speaking of the absence of any stock market bubbles and balanced correlation between the stock market and the economy of the country [8].

External and internal factors producing the largest impact on the ratio dynamics have been selected on the factor analysis step, namely: the M2X aggregate, MIACR, Brent oil and UST-10 yield. The correlation and regression analysis has exhibited the absence of co-integration in the MIACR and UST-10 yield ranges with the MOEX ratios showing that the influence of these factors on the Russian stock market dynamics is statistically insignificant. As a result, a twofactor model has appeared. We have further determined the bubble's part in the current index value by calculating the amount of excess of the market ratio value over the generated model values. The indicator value is reaching the top threshold of $30 \%$. This suggests a possibility for the origination of a new financial bubble especially in the conditions when the ratio reaches new historical maximum values for the recent time.

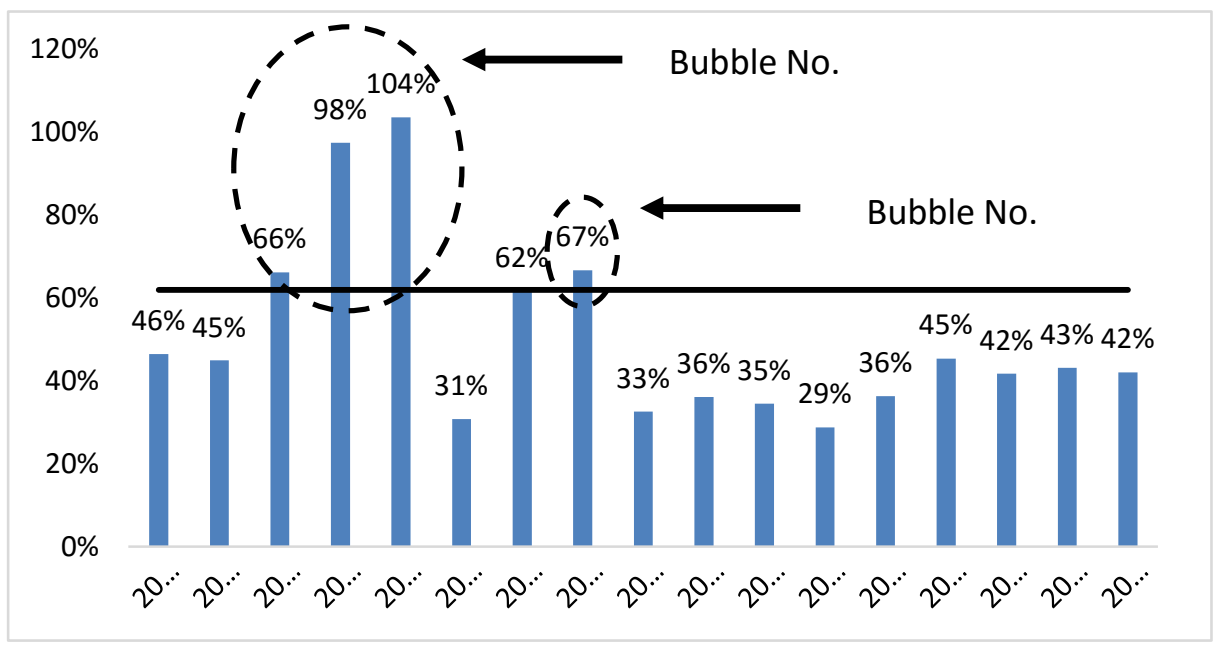

Fig. 1. MCap/GDP dynamics (Source: Authors).

The fractal analysis is used to determine the dependence between the future asset prices and their previous changes. The Hurst exponent serves as the quantitative expression of fractal processes as it measures 'roughness' of a time series and makes it possible to single out ranges of excessive cumulative dependence of observed values [9]. The Russian stock market really has a long memory. As soon as the exponent reaches the threshold value (0.75), the market 'remembers' the previous dynamics and aims at repeating it. The Hurst exponent reached 0.71 in March 2019, which is fairly close to the border, but there is no question of the possibility of a catastrophe yet.

The received results attest to the fact that the stock market is now on the growing stage, without any obvious bubble origination symptoms as only one of the four indicators has exhibited a possibility for the origination of a bubble on the Russian market [10]. The other ratios speak of the absence of such possibility. However, some of them are nearing the border. For example, the ratios received following the factor analysis is just $9 \%$ below the threshold. Taking into account the information cascading effect and the market dynamics being quite good lately, these $9 \%$ can quickly turn to nothing. The fractal analysis is also demonstrating the proximity of the calculated and threshold values meaning that if the level of 0.75 is reached in the nearest future, there will most probably appear a market bubble. 
The results of the macroeconomic environment analysis point to the economically justified correlation between the stock market and the country GDP in March 2019 from the standpoint of bubble identification. It means that the origination of the latter in such conditions is unlikely.

\section{Conclusion}

Thus, the following conclusions have been made as a result of a complex stock market bubble analysis. Firstly, the built model is adequately reflecting the earlier originated stock market bubbles proving that it is fit for use. Secondly, the model characterizes various stock market sides: identification of any deviations in any sphere will immediately point at the reasons for anomalies on the stock market. For example, the main problem of the share market today is of behavioral character, i.e. the participants are prone to collective actions.

\section{References}

1. D.K. Tarullo, Financial regulation: Still unsettled a decade after the crisis. Journal of Economic Perspectives, 33(1), 61-80 (2019).

2. A.J. Makin, Lessons for macroeconomic policy from the global financial crisis. Economic Analysis and Policy, 64, 13-25 (2019).

3. A. Volkova, A review of government programs. Procedia Economics and Finance, 27, $484-493$ (2015). DOI: 10.1016/S2212-5671(15)01025-4.

4. G.Zhang, W. Liu, Analysis of the international propagation of contagion between oil and stock markets. Energy, 165, 469-486 (2018). DOI: 10.1016/j.energy.2018.09.024.

5. M.L. Dorofeev, G.V. Samarskiy, Modelling of financial bubble processes on the Russian stock market. Finance and Credit, 15, 45-62 (2016). [in Rus.].

6. A.V. Zinenko, R/S Analysis on a stock market. Business Informatics, 3(21), 24-30 (2012). [in Rus.].

7. E.F. Fama, Efficient capital markets: A review of theory and empirical work. The Journal of Finance, 25(2), 383417 (1970).

8. Ch. P. Kindleberger, R. Aliber, Manias, panics and crashes: A history of financial crises (Peter, Saint Petersburg, 2012). [in Rus.].

9. E .Majewska, J. Olbryś, The evolution of financial integration on selected European stock markets: A dynamic principal component approach. Comparative Economic Research, 20(4), 45-63 (2017). DOI: 10.1515/cer-2017-0027.

10. D. Duffie, Prone to Fail: The pre-crisis financial system. Journal of Economic Perspectives, 33(1), 81-106 (2019). DOI: $10.1257 /$ jep.33.1.81.

11. A. Kireyev, A. Leonidov, Network effects of international shocks and spillovers. Networks and Spatial Economics, 18(4), 805-836 (2018). 